\title{
FRP-TO-MASONRY BOND DURABILITY ASSESSMENT WITH INFRARED THERMOGRAPHY METHOD
}

\section{Bahman Ghiassi ${ }^{1}$, Sandra M. Silva ${ }^{2}$, Daniel V. Oliveira ${ }^{3}$, Paulo B. Lourenço ${ }^{4}$, Luís Bragança $^{5}$}

\begin{abstract}
The bond behavior between FRP composites and masonry substrate plays an important role in the performance of externally bonded reinforced masonry structures. Therefore, monitoring the bond quality during the application and subsequent service life of a structure is of crucial importance for execution control and structural health monitoring. The bond quality can change during the service life of the structure due to environmental conditions. Local detachments may occur at the FRP/substrate interface, affecting the bond performance to a large extent. Therefore,
\end{abstract}

${ }^{1}$ PhD Student, ISISE, University of Minho, Department of Civil Engineering, Azurém, 4800-058 Guimarães, Portugal. Phone: +351 253510 499, fax: +351 253510 217, E-mail:

bahmanghiassi@civil.uminho.pt

${ }^{2}$ Assistant Professor, University of Minho, Department of Civil Engineering, Azurém, 4800-058 Guimarães, Portugal. Phone: +351 253510 200, fax: +351 253510 217, E-mail:

sms@civil.uminho.pt

${ }^{3}$ Associate Professor, ISISE, University of Minho, Department of Civil Engineering, Azurém, 4800-058 Guimarães, Portugal. Phone: +351 253510 247, fax: +351 253510 217, E-mail: danvco@civil.uminho.pt

${ }^{4}$ Professor, ISISE, University of Minho, Department of Civil Engineering, Azurém, 4800-058 Guimarães, Portugal. Phone: +351 253510 209, fax: +351 253510 217, E-mail: pbl@,civil.uminho.pt

${ }^{5}$ Associate Professor, University of Minho, Department of Civil Engineering, Azurém, 4800-058 Guimarães, Portugal. Phone: +351 253510 241, fax: +351 253510 217, E-mail: braganca@civil.uminho.pt 
the use of expedite and efficient non-destructive techniques for assessment of the bond quality and monitoring FRP delamination is of much interest.

Active infrared thermography (IR) technique was used in this study for assessing the bond quality in environmentally degraded FRP-strengthened masonry elements. The applicability and accuracy of the adopted method was initially validated by localization and size quantification of artificially embedded defects in FRP-strengthened brick specimens. Then, the method was used for investigating the appearance and progression of FRP delaminations due to environmental conditions. GFRP-strengthened brick specimens were exposed to accelerated hygrothermal ageing tests and inspected periodically with the IR camera. The results showed environmental exposure may produce large progressive FRP delaminations.

Keywords: IR thermography; Bond; FRP; masonry; Durability; Accelerated testing. 


\section{Introduction}

Externally bonded composites with fiber reinforced polymers (FRPs) became popular in the last decades for strengthening masonry structures. Advantages such as low weight to strength ratio, high mechanical properties, and ease in application have made these materials a suitable solution for this purpose. However, the performance of the strengthened structure depends intrinsically on the bond between the composite material and the masonry substrate. Failure of the bond interface may lead to deterioration of composite action or premature debonding. Therefore, a sound understanding of the interface behavior is crucial for design and assessment purposes. Although extensive experimental and numerical studies have been performed on the short-term performance of bond in FRP strengthened masonry elements [1-3], its durability and long-term behavior of bond are still an open issues [4].

Environmental conditions can cause bond degradation and FRP delaminations in the interfacial region which affect the performance of the strengthened structure. Moisture presence in the interfacial region causes reduction of bond strength and fracture energy [5-7]. Moreover, the failure mode often changes from cohesive to adhesive, and the bond force-slip diagrams show a non-linear trend at a lower applied force. These observations are usually attributed to the extensive moisture plasticization of the polymer adhesive and additional breakage of interfacial bonds [8]. Temperature cycles, keeping the temperature below the epoxy glass transition temperature, may cause degradation of bond and FRP delaminations due to the imposed thermal fatigue or thermal incompatibility problem [4]. Furthermore, exposure to subzero temperatures and freeze-thaw cycles were shown to cause degradation in the bond behavior [9]. Interfacial flaws and defects can also be produced due to chemical incompatibility between the 
strengthening material and the substrate or poor workmanship, especially in wet lay-up applications.

Partial destructive tests such as pull-off tests have been conventionally used for investigating the bond quality during the service life of a structure or in experimental testing programs. However, these tests are regarded as localized tests, with local loss of strengthening material, and they do not allow to carry out extensive investigations in terms of location or through the structural lifetime [3]. There is thus a need for development and use of nondestructive tests that can provide useful information on the bond condition and allow extensive inspections.

This study focuses on the use of IR thermography technique for detection, localization and quantification of environmentally induced FRP delaminations in FRP-strengthened masonry elements. The infrared (IR) thermography technique has been accepted as an effective method for detection of bond defects in composite structures [10-15]. The application of this method in detection of FRP-strengthened concrete elements has received extensive attention in the last years [10-13], while the information on FRP-strengthened masonry is rare. The technique has been successfully used for detection and quantification of artificial defects, see e.g. [12], or delamination progress during mechanical tests on FRP-strengthened concrete beams, see e.g. [15]. Meanwhile, the information on the use of this technique for durability assessment is very limited, see e.g. [13]. Although, the previous research shows the applicability of this technique for bond assessment and health monitoring purposes, an extensive investigation on the applicability of this method to FRP-strengthened masonry and detection of bond delaminations due to environmental conditions is required. 
A quantitative IR thermography method previously used in [12] was adopted and used here for detection of the environmentally induced delaminations in GFRP-strengthened masonry systems. The applicability and accuracy of the adopted method was initially validated by localization and size quantification of artificially embedded defects (with different sizes) in FRPstrengthened brick specimens. Once the procedure was validated and the test setup was optimized, detection of FRP delaminations induced due to environmental hygrothermal conditions is addressed. The environmental conditions were simulated by performing accelerated ageing tests on the specimens inside a climatic chamber. The appearance and progression of FRP delaminations were monitored with the quantitative IR thermography method and the results are presented and discussed.

\section{IR thermography method}

\subsection{Principles}

The IR thermography method has been extensively used in the last years for detection and evaluation of defects in FRP bonded components [16,17,12]. Applications are mostly focused on qualitative assessment and localization of the defects. However, once the defects have been located, it is interesting to characterize them quantitatively in order to evaluate the structure performance. Infrared thermography methods can be divided into passive infrared thermography (PIT) and active infrared thermography (AIT) techniques. The difference between these two methods is that external surface heating is required in the AIT, while in the PIT no external heating is applied and the natural surface temperature of the specimen is monitored and analyzed. In other words, in AIT, heat energy is applied to the specimen and the surface response to this energy is analyzed for localization and evaluation of the defects or material 
discontinuities. Alternatively, the surface temperature of the specimen at ambient conditions is monitored in PIT without application of any heat energy [18]. Suspicious defects and flaws can be distinguished from abnormal temperature profiles on the surface. Special care should be taken in interpretation of the results since anomalous thermal gradients can also be produced due to non-uniform heating or reflection effects.

The main approaches used for surface external heating in AIT technique are pulse heating, step heating, and lock-in thermography [18]. In pulse heating method, a short burst of heat energy is applied to the specimen's surface and thermal images are captured during the surface cooling process. Step heating consists of application of lower intensity heat energy with a longer duration. In this technique, thermal imaging is conducted during the heating process. Finally, lock-in thermography is similar to the step heating process, with the difference that the applied heat energy is sinusoidal.

Pulse heating and lock-in thermography methods have been used more extensively for nondestructive evaluation purposes [19]. Each of these methods has different advantages and disadvantages. The main limitations of the pulse heating method are the area that can be uniformly heated and inspected, and the depth in which the defect can be detected. In the lock-in thermography method, larger areas can be inspected and defects at greater depths can be detected. However, each frequency of modulation is related to a special defect depth [19]. Therefore, for inspecting the specimens in their full depth, a range of exposure frequencies should be adopted, and this increases the number of required tests to a large extent. Since FRP delaminations from the masonry substrate are interfacial, the step heating method has been used in this study. Fast and light heaters are available for practical applications, even if difficulties might arise in practical applications on very large structures (e.g. bridges) or rendered FRP 
applications. For non-rendered applications and for research purposes on the performance and durability of bond, no difficulties occur.

Generally, the adoption of IR thermography technique for evaluation of bond quality is based on the fact that the heat flux is transmitted at different rates in materials with different thermal properties. In a FRP-strengthened element, any defect or delamination in the interfacial region changes the thermal properties in that area. Therefore, if a heat flux is applied to the surface of a FRP-bonded element, the heat will be transferred with a different rate in the defected areas with respect to the perfectly bonded regions. This leads to the appearance of hot or cold spots in thermal images depending on the heat observation method [16]. Heat observation methods can be categorized as reflection and transmission methods. In the reflection observation method, see Fig. 1(a), the heat source and IR camera are placed at the same side of the specimen and the emitted heat from the specimen's surface is detected and captured as thermal images. In this method, defects appear as hot spots in the thermal images. Alternatively, the heat source and IR camera can be located in opposite sides of the specimen (transmission observation method) and the transmitted heat through the specimen's depth is measured on the surface under investigation, see Fig. 1 (b). In this method, the defects appear as cold spots in the thermal images. In the reflection observation method, higher resolution is obtained but the thickness of the material that can be investigated is small. The transmission observation method allows inspection of materials with larger thickness but the information through depth is lost $[18,20,21]$. The present study focused on the use of reflection observation method in detecting interfacial delaminations. 


\subsection{Quantitative IR thermography}

In quantitative IR thermography, besides localization of defects or flaws, the physical characteristics of them, such as dimensions, depth and shape, can also be evaluated. Quantitative analysis can be performed following direct analytical methods or inverse methods [18,22]. Direct analytical methods involve analytical modeling of thermal transfer and propagation inside the material for interpretation of the experimental results. While these models are straightforward in simple conditions, they become complex when the material is not isotropic and the surface roughness of the specimen is taken into account [18]. Inverse methods involve obtaining the defect parameters from the thermographic signals $[12,17]$.

As described before, in the pulse thermography technique some heat energy is applied to the specimen for a short period and sequential thermal images are taken from the surface during the cooling process. After application of the heat energy, the temperature decays with time and the resolution of the observed defects changes at different moments. Infrared images are generally noisy and have a low signal-to-noise ratio. Several post-processing techniques are therefore used for further enhancement of the thermal images and quantification of the defects such as thermal contrast technique, thermographic signal reconstruction, pulse phase thermography and principal component thermography [23,24].

Thermal contrast method is the most simple and common method used for processing thermographic data. In this method the suitable thermogram is the one that has the maximum contrast between defective and sound areas [18]. The Thermal Signal Reconstruction technique also well known as TSR is used to reduce high frequency temporal noise and amount of data to be manipulated while increasing the spatial and temporal resolution of thermal sequence. In this method it is assumed that the temperature profile of sound areas follow the decay curve given by 
the 1D solution of Fourier transform. The Pulse phase thermography technique is applied on the thermal sequences using Fourier transform equations. This approach combines the advantages of modulated and pulse infrared thermography through unscrambling the various frequencies launched in pulse infrared thermography and only conservation of the maximum phase components in the corresponding Fourier spectrum [25]. Comparing to thermal contrast method, these methods have the advantage that locating a sound area is not necessary during the analysis and higher image enhancements at greater depths are obtained. Thermal contrast method has been observed to be sufficiently accurate for FRP bonded systems [13,17] and therefore is adopted in this study.

In thermal contrast method, before application of any analytical algorithm for evaluating the physical properties of the defects, the selection of an appropriate thermogram with the best contrast and resolution is necessary to obtain the highest possible accuracy. Several types of contrasts are defined in the literature such as absolute contrast, differential contrast and normalized contrast [26]. All the contrast methods require having a sound area in the thermogram. This problem has been solved with differential absolute contrast (DAC) [27] in which it is assumed that all the points behave as a sound area in the first few images. The absolute contrast method is applied in this study as also adopted before for FRP bonded systems.

It is usually considered that the most appropriate thermogram is the one with the maximum thermal contrast $[17,12]$. Once the most appropriate thermogram has been selected, the size of different defects can be estimated with an adequate algorithm. Several algorithms are proposed by different researchers such as high degree approximation, second order fit and inflection point $[12,23]$. The two-point inflection method has been selected here, as it was previously used for 
detection of flaws and defects in FRP-strengthened concrete elements with reasonable results in [12]. Details about these procedures are addressed next.

\subsubsection{Maximum thermal contrast}

Fig. 2 shows a typical temperature history of a defect and a sound area obtained from IR thermography tests. The time corresponding to the maximum thermal contrast is defined as the time in which the temperature difference between the sound and defect area is maximum (defined as absolute contrast) [18], see Fig. 2. Therefore, the thermogram corresponding to the peak value of the difference curve should be selected for performing the quantitative analysis.

\subsubsection{Inflection point method}

In this method it is assumed that the boundaries of the defects are the inflection points of a fourth order polynomial that is fitted through the temperature profile along the flaw [12]. Fig. 3 shows the longitudinal and vertical temperature profiles of a defect in a sample thermogram. The

temperature profile around the defect can be divided into two parts from its center point (left and right). Each part can be estimated with a fourth order polynomial and the inflection points are assumed to be the respective defect boundaries. The total length of the defect along the section under investigation can be obtained by measuring the distance between the two calculated boundaries, see Fig. 4. To avoid dependency of the results on the defect's selected center point, each calculation has been conducted three times considering a confidence level of $5 \%$ for the center point selection. In other words, center point has been moved 5\% forwards and backwards and the calculations have been repeated. The results are then presented as the average value of three boundary locations obtained for each zone. It is noted that the approximation should be conducted at different sections and angles along the localized defect for accurately evaluating its area and shape. 


\section{Methodology validation}

The accuracy of the adopted method in detection and quantification of the interfacial defects in FRP-strengthened masonry elements has been validated in this section. For this reason, GFRPstrengthened bricks specimens with artificial embedded defects of different sizes and locations were prepared and tested with the adopted IR thermography method.

\subsection{Specimens preparation}

Unidirectional glass fibers (MapeWrap G UNI-AX) were used for strengthening the masonry bricks. According to the technical datasheets provided by the manufacturer, the glass fibers are E-glass with density of $2.62 \mathrm{~kg} / \mathrm{dm}^{2}$ and equivalent thickness of $0.48 \mathrm{~mm}$. The GFRP sheets were applied on the brick surface following the wet lay-up procedure. Solid cay bricks with dimensions of $200 \times 100 \times 50 \mathrm{~mm}^{3}$ are used in this study as substrate. The masonry bricks were dried in the oven before application of the GFRP sheets. After cleaning the bricks surfaces, artificial defects were attached to the surface. The embedded defects were circular plastic strips with diameters of 5, 10, 15, 20, and $25 \mathrm{~mm}$, see Fig. 5(a). Although the effect of smaller defects, less than $10 \mathrm{~mm}$, on the global bond behavior may be negligible, their selection was necessary for understanding the minimum detectable defect size. Then, a compatible two-part epoxy primer (MapeWrap Primer 1) was carefully applied to the brick surface for preparation of the substrate surface before application of the glass fibers. Finally, a two-part epoxy resin (MapeWrap 31) was used as the matrix of the composite material and adhesion to the masonry substrate. The selected primer and epoxy resins are a transparent yellow epoxy resin with a low and medium viscosity, respectively. 
The plastic strips were glued to the brick surface only at their extreme boundaries, see Fig. 5(b). Therefore, not only the movement of the strips was avoided during the FRP application, but also an artificial delaminated area was produced under the strips where there was no bond between GFRP sheets and the brick surface.

The specimens were cured for one month in the laboratory conditions before performing the IR thermography tests.

\subsection{IR thermography test}

The tests were performed with a FLIR ThermaCAM T400 infrared camera with spectral range of $7.5-13 \mu \mathrm{m}$ and thermal sensitivity of $<0.07 \mathrm{C}$. Thermal videos were recorded at the rate of 9 frame/sec, at the cooling stage. The recorded videos were converted into sequential 8-bit digitized photos of $320 \times 240$ pixels for each recorded frame. In 8-bit formatting system each pixel has a value between 0 to 255 , which represents different colors and temperature variations in a linear scale. The data for each test was converted into $3 \mathrm{D}$ matrices with the size of $320 \times 240 \times t$, where the third dimension of the matrix represents time. The temperature decay through time and analysis of the thermal images were then performed through a Matlab code specially developed.

Two lamps with a maximum power of $2000 \mathrm{~W}$ were used as heating sources. The lamps were placed at $500 \mathrm{~mm}$ distance from the specimens, for 30 seconds. The position and duration

of the heat exposure were optimized to obtain the best uniform heat distribution on the specimens' surfaces.

\subsection{Results and discussion}

The temperature history curves of defects with different sizes are shown in Fig. 6. These curves are obtained at the pixel corresponding to the centroid of each defect. It can be observed 
that the temperature decay in $5 \mathrm{~mm}$ defect is similar to the sound area showing that this defect was not detected with the adopted IR thermography method. The minimum defect size that was detected in the thermal images was $10 \mathrm{~mm}$. It is also shown that the temperature decay in 15,20 , and $25 \mathrm{~mm}$ defects are much different from the decay in $10 \mathrm{~mm}$ defect. For this reason, the maximum thermal contrast for $10 \mathrm{~mm}$ defect has been obtained separately from the other defect sizes, see Fig. 7. It can be observed that the maximum thermal contrast for 10 and $25 \mathrm{~mm}$ defects occur at 4 and $5.5 \mathrm{~s}$ of thermal imaging (being slightly different), respectively. The corresponding thermograms have been then selected for evaluating the defects sizes.

The defect dimensions have been calculated following the two-point inflection method. The calculations have been performed at longitudinal and transverse sections of each defect to obtain the defect's diameter in both directions, see Table 1. Then, assuming the defect as an ellipse, the area of each defect was calculated. The predicted defects' areas are also given for different defect sizes as normalized to the actual defect area. It can be observed that the defect sizes larger than $10 \mathrm{~mm}$ diameter have been predicted with a high degree of precision, with a maximum error lower than $10 \%$. However, the error for the $10 \mathrm{~mm}$ defect size is relatively high (18\%). The results validate the accuracy and high precision of the IR analysis technique used in this study for GFRP-strengthened masonry elements. Similar observations were reported in [12] for detecting the embedded flaws in CFRP-strengthened concrete elements.

\section{Application to bond durability}

The applicability of the adopted IR thermography technique in detection of environmentally induced FRP delaminations is investigated in this section. Environmental conditions were simulated by exposing GFRP-strengthened brick specimens to accelerated 
hygrothermal tests. The specimens were inspected visually and tested after each fifty cycles of exposure to obtain the bond degradation behavior through time.

The assessment procedure consisted of two main steps. First, the existence of FRP delaminations in the specimens was controlled by visual inspection and qualitative IR thermography method. Due to the transparency of the epoxy resin, FRP delaminations were detectable even with visual inspection. Therefore, this technique was used for validating the applicability of the qualitative IR thermography in detection and localization of induced interfacial delaminations. The results showed progressive FRP delaminations in the specimens with time. After localization of the delaminations, their size and boundaries were evaluated with the quantitative IR thermography method described in sec. 2. The adopted IR test setup and instrumentations were the same as the ones used for detection of artificial defects, see sec.3.2.

\subsection{Specimens preparation and testing}

Unidirectional GFRP sheets with $50 \mathrm{~mm}$ width were applied to the bricks surfaces following the wet lay-up procedure. The specimens were prepared following the same procedure as described in sec. 3.1. Step-by-step preparation procedure and geometrical details of the specimens are shown in Fig. 8 and Fig. 9.

\subsection{Environmental exposure}

The specimens were exposed to two different accelerated hygrothermal conditions in a climatic chamber. The aim was to investigate the coupling effect of temperature cycles and moisture on the bond behavior. The details of the exposure conditions are shown in Fig. 10.

In the first exposure, HT, the specimens were exposed to $6 \mathrm{hr}$ temperature cycles from $+10^{\circ} \mathrm{C}$ to $+50^{\circ} \mathrm{C}$ and constant relative humidity of $90 \%$. In each cycle, the temperature was kept constant at $+10^{\circ} \mathrm{C}$ for $2 \mathrm{hr}$. The temperature was then increased to $+50^{\circ} \mathrm{C}$ in $1 \mathrm{hr}$, followed by $2 \mathrm{hr}$ 
constant temperature at $+50^{\circ} \mathrm{C}$. Finally, the temperature was decreased again to $+10^{\circ} \mathrm{C}$ in $1 \mathrm{hr}$ resulting in $6 \mathrm{hr}$ cycles of exposure. In the second exposure, FT, the specimens were exposed to temperature cycles from $-10^{\circ} \mathrm{C}$ to $+30^{\circ} \mathrm{C}$ and, again, constant relative humidity of $90 \%$. The aim was to investigate the effect of freeze-thaw on the bond behavior, while having a minimum number of changes comparing to the first exposure. Therefore, similar exposure cycle rates have been adopted with a $20^{\circ} \mathrm{C}$ decrease of the maximum and minimum temperatures. The specimens were subjected to a total of 200 cycles in each exposure condition.

\subsection{Results and discussion}

Five specimens were taken out of the climatic chamber after each fifty cycles of exposure. Visual inspection and IR thermography tests were performed on the specimens after four days of drying and stabilized in laboratory conditions.

Fig. 11 shows typical examples of specimens for each exposure period. Visual inspection and qualitative IR thermography were used for localization of FRP delaminations. Relatively large FRP delaminations were observed in the specimens exposed to HT conditions. On the contrary, the specimens exposed to FT conditions had very small delaminations. The thermal images and detected FRP delaminated areas, from IR thermography tests, for the specimens exposed to HT conditions are presented in Fig. 12. It can be observed that the FRP delaminations progressively increased with the exposure time. It should be noted that due to the physical properties of the materials used in this study, delaminations were also observable with visual assessment. This advantage could assist us in validating the IR technique in localization of interfacial delaminations. However, in case of strengthening with other composite materials and matrices or application of renderings over the strengthening visual observation is not applicable. 
The observed FRP delaminations can be attributed to the thermal incompatibility between materials. However, moisture can also play an important role in weakening the bond strength [57]. The thermal expansion coefficient of clay bricks is in the order of $5 \times 10^{-6} \% \mathrm{C}$ [28]. The thermal expansion coefficient of E-glass fibers is similar to the clay bricks, while for the epoxy resin is in the range of $3 \sim 5 \times 10^{-5} \mathrm{r}$ [29]. This one-order magnitude difference of thermal expansion coefficient between epoxy resin and glass fibers/bricks produces large interfacial thermal stresses at the fiber/epoxy and brick/epoxy interfaces. Cyclic temperature conditions induce thermal fatigue and may cause FRP delaminations from the brick surface during the environmental exposure. The smaller delaminated areas observed in the specimens exposed to the FT conditions, can be explained with the fact that the thermal expansion coefficient of epoxy resins is much lower at low and negative temperatures [30].

Once the delaminations were localized, the captured thermograms were analyzed according to the two-point inflection method to quantify the FRP delaminated areas. For this reason, the temperature profiles were obtained along the bonded length at longitudinal sections (trying to obtain the edge lines and the center line of the delamination area), see e.g. Fig. 13 to Fig. 15. Then, the temperature profiles near the detached areas were fitted with a $4^{\text {th }}$ order polynomial curve. The inflection point of the estimated curve was selected as the boundary of the FRP delaminated area. Fig. 13 to Fig. 15 show also this calculation process in two different specimens exposed to 100 and 200 cycles of HT conditions.

In the specimen exposed to 100 cycles, delamination was observed in the center of the bonded length, shown as a hot spot in the thermogram presented in Fig. 13. Therefore, it was necessary to obtain the boundaries of the delaminated area on both sides of the defect in the longitudinal direction, as indicated in Fig. 14. However, the delamination in the specimen 
exposed to 200 cycles started from the loaded end of the specimen and progressed along the bonded length, see Fig. 15. Therefore, just one boundary in the longitudinal direction should be located for obtaining the delamination size. The large FRP delaminated area in the specimen exposed to 200 cycles of HT exposure shows the severity of the thermal incompatibility in the specimens used in this study.

The results of the quantitative IR thermography are presented in Fig. 16 as the remaining bonded area normalized to the initial bonded area. The presented values are obtained as the average of five tested specimens. $23 \%$ reduction of bonded area after 200 cycles of HT exposure can be observed, while the reduction in the bonded area in the specimens exposed to FT conditions is very limited ( $2 \%$ after 200 cycles).

\section{Conclusions}

Active IR thermography technique was used for detection and quantification of environmentally induced FRP delaminations from masonry substrate. The adopted quantitative algorithm was based on the two point inflection point method. The applicability of this method for detecting FRP delaminations in GFRP-strengthened masonry elements was initially validated using specimens with interfacial embedded defects of different sizes. The IR thermography results showed that the adopted method can be suitably used for detecting defects with a minimum size of $10 \mathrm{~mm}$ with a reasonable accuracy in size quantification.

Once the method was validated and test setup optimized, it was used for detection of environmentally induced FRP delaminations. The environmental conditions were simulated by exposing the specimens to two different accelerated hygrothermal conditions in a climatic chamber. The aim was to investigate the coupling effect of temperature and moisture on the bond 
quality. The specimens consisted of GFRP-strengthened brick specimens prepared following the wet lay-up procedure. The IR thermography tests and visual inspection were performed periodically after each fifty cycles of exposure. Progressive FRP delaminations were observed in the specimens after exposure to environmental conditions. The observed delaminations, being more severe in specimens exposed to HT conditions, can be attributed to the thermal incompatibility between materials and induced thermal fatigue on the specimens. The size of delaminated areas was evaluated quantitatively with the adopted IR thermography method and the results were presented.

The obtained results showed the applicability of IR thermography technique bond health assessment in durability studies for research purposes as well as onsite monitoring in cases in which the FRP surface is not protected with any renderings. However, application of this technique for far field assessments or in cases in which a protective rendering mortar is applied on the FRP surface remains open requiring further investigations.

\section{Acknowledgements}

This work was partly funded by project FP7-ENV-2009-1-244123-NIKER of the $7^{\text {th }}$ Framework Program of the European Commission, which is gratefully acknowledged. The first author also acknowledges the financial support of the Portuguese Science Foundation (Fundação de Ciência e Tecnologia, FCT), through grant SFRH/BD/80697/2011. 


\section{References}

1. Ghiassi B, Marcari G, Oliveira DV, Lourenço PB (2012) Numerical analysis of bond behavior between masonry bricks and composite materials. Eng Struct 43:210-220.

2. Ghiassi B, Oliveira DV, Lourenço PB, Marcari G (2012) Numerical study of the role of mortar joints in the bond behavior of FRP-strengthened masonry. Compos B 46:21-30.

3. Oliveira D, Basilio I, Lourenço P (2011) Experimental bond behavior of FRP sheets glued on brick masonry. J Compos Constr, ASCE 15 (1):32-41.

4. Karbhari VM, Chin W, Hunston D, Benmokrane B, Juska T, Morgan R, Lesko JJ, Sorathia U, Reynaud D (2003) Durability gap analysis for fiber-reinforced polymer composites in civil infrastructures. J Compos Constr 7 (3):238-247.

5. Ghiassi B, Marcari G, Oliveira DV, Lourenço PB (2012) Water degrading effects on the bond behavior in FRP-strengthened masonry. Compos Part B 54:11-19.

6. Lau D, Buyukozturk O (2010) Fracture characterization of concrete/epoxy interface affected by moisture. Mech Mater 42 (12):1031-1042.

7. Sciolti MS, Aiello MA, Frigione M (2012) Influence of water on bond behavior between CFRP sheet and natural calcareous stones. Compos Part B 43 (8):3239-3250.

8. Wan B, Petrou MF, Harries KA (2006) Effect of the presence of water on the durability of bond between CFRP and concrete. J Reinf Plast Compos 25 (8):875-890.

9. Colombi P, Fava G, Poggi C (2010) Bond strength of CFRP-concrete elements under freezethaw cycles. Compos struct 92 (4):973-983.

10. Tashan J, Al-mahaidi R (2012) Investigation of the parameters that influence the accuracy of bond defect detection in CFRP bonded specimens using IR thermography. Compos Struct 94 (2):519-531. 
11. Taillade F, Quiertant M, Benzarti K, Aubagnac C (2011) Shearography and pulsed stimulated infrared thermography applied to a nondestructive evaluation of FRP strengthening systems bonded on concrete structures. Constr Build Mater 25 (2):568-574.

12. Lai WL, Kou SC, Poon CS, Tsang WF, Lai CC (2010) Characterization of the deterioration of externally bonded CFRP-concrete composites using quantitative infrared thermography. Cem Concr Compos 32:740-746.

13. Lai CC, Kou SC, Poon CS, Tsang WF, Lee KK (2013) A durability study of externally bonded FRP-concrete beams via full-field infrared thermography (IRT) and quasi-static shear test. Constr Build Mater 40:481-491.

14. Li Z, Yao W, Lee S, Lee C, Yang Z (2000) Application of Infrared Thermography technique in building finish evaluation. J Nondestruct Eval 19 (1):11-19.

15. Valluzzi M, Grinzato E, Pelegrino C, Modena C (2009) IR thermography for interface analysis of FRP laminates externally bonded to RC beams. Mater Struct 42:25-34.

16. Tashan J, Al-mahaidi R (2012) Investigation of the parameters that influence the accuracy of bond defect detection in CFRP bonded specimens using IR thermography. Compo Struct 94 (2):519-531.

17. Lai WL, Kou SC, Poon CS, Tsang WF, Ng SP, Hung YY (2009) Characterization of flaws embedded in externally bonded CFRP on concrete beams by infrared thermography and shearography. J Nondestruct Eval 28:27-35.

18. Maldague X (2001) Theory and practice of infrared technology for nondestructive testing. Wiley-Interscience, John Wiley\&Sons Inc.

19. Brown J, Hamilton H (2013) Quantitative infrared thermography inspection for FRP applied to concrete using single pixel analysis. Constr Build Mater 38:1292-1302. 
20. Reynolds WM (1985) Quality control of composite materials by thermography. Mater Struct $1(2): 100-102$.

21. Sayers CM (1984) Detectibility of defects by thermal non-destructive testing. Br J NDT 26 (1):28-33.

22. Krapez J, Cielo P (1991) Thermographic nondestructive evaluation: data inversion procedures part I: 1D analysis. Res Nondestruct Eval 3(2):81-100.

23. ASNT (2001) Nondestructive Testing Handbook. III edition, vol. 3, Infrared and Thermal Testing, ed. X. Maldague.

24. Castanedo IC, Piau JM, Guilbert S, Avdelidis NP, Genest M, Bendada A, Maldague XPV (2009) Comparative study of active thermography techniques for the nondestructive evaluation of honeycomb structures. Res Nondestruct Eval:1-31.

25. Maldague X, Marinetti S (1996) Pulse phase infrared thermography. J App Phys 79 (5):2694.

26. Benitez HD, Ibarra-Castanedo C, Bendada A, Maldague X, Loaiza H, Caicedo E (2008)

Definition of a new thermal contrast and pulse correction for defect quantification in pulsed thermography. Infrared Phys Technol 51:160-167.

27. Pilla M, Klein M, Maldague X, Salerno A New Absolute Contrast for Pulsed Thermography. In: D. Balageas GB, G. Carlomagno (eds) Proc. of QIRT, 2002. pp 53-58.

28. Kralj B, Pande GN, Middleton J (1991) On the mechanics of frost damage to brick masonry. Compos Struct 41 (1):53-66.

29. CNR-DT 200 (2004) Guide for the design and construction of externally bonded FRP systems for strengthening existing structures. CNR-DT 200/2004. National Research Council, Rome. 
30. Dohnalek P (2006) Environmental durability of FRP bond to concrete subjected to freezethaw action., Master Thesis, MIT. 


\section{List of Tables}

Table 1. Predicted defect diameters.

\section{List of Figures}

Fig. 1. Different heat observation methods in IR thermography technique: (a) reflection observation method; (b) transmission observation method.

Fig. 2. Thermal history curves of sound and delaminated areas.

Fig. 3. Thermogram of a defect.

Fig. 4. Defect boundaries. Zone 1 and Zone 2 represent different left and right sections of the defect around the center point.

Fig. 5. Details of the specimens with embedded interfacial defects: (a) defects details; (b) attachment details.

Fig. 6. Thermal history curves at defect locations and a typical thermogram.

Fig. 7. Maximum thermal contrast evaluation for: (a) $10 \mathrm{~mm}$ defect; (b) $25 \mathrm{~mm}$ defect.

Fig. 8. Preparation of the brick specimens following the wet lay-up procedure.

Fig. 9. Details of the specimens used for accelerated ageing tests.

Fig. 10. Accelerated hygrothermal exposures for two different diagrams (FT and HT).

Fig. 11. Specimens exposed to different periods of: (a) HT exposure; (b) FT exposure.

Fig. 12. Qualitative assessment of delaminated areas after different periods of exposure to HT conditions, using IR tomography.

Fig. 13. Temperature profiles in a specimen exposed to 100 cycles of HT exposure.

Fig. 14. Delamination boundaries evaluation in a specimen exposed to 100 cycles of HT exposure.

Fig. 15. Temperature profiles and quantitative assessment of delaminated areas in a specimen exposed to 200 cycles of HT exposure.

Fig. 16. Reduction of the bonded area with exposure cycles. 
Table 1. Predicted defect diameters.

\begin{tabular}{cccc}
\hline & \multicolumn{3}{c}{ IR thermography prediction } \\
Actual $\begin{array}{c}\text { defect } \\
\text { diameter } \\
(\mathrm{mm})\end{array}$ & $\begin{array}{c}\text { Horizontal diam., } \\
d_{1} \\
(\mathrm{~mm})\end{array}$ & $\begin{array}{c}\text { Vertical diam., } d_{2} \\
(\mathrm{~mm})\end{array}$ & $\begin{array}{c}\text { Pred./Actual } \\
\text { area }\end{array}$ \\
\hline 10 & $11.0($ err. $10.0 \%)$ & $11.8($ err. $18.0 \%)$ & 1.30 \\
\hline 15 & $15.9($ err. $6.0 \%)$ & $15.1($ err. $0.7 \%)$ & 1.07 \\
\hline 20 & $21.0($ err. $8.4 \%)$ & $18.5($ err. - $7.5 \%)$ & 0.97 \\
\hline 25 & $24.7($ err. $-1.2 \%)$ & $24.5($ err. $-2.0 \%)$ & 0.96 \\
\hline
\end{tabular}




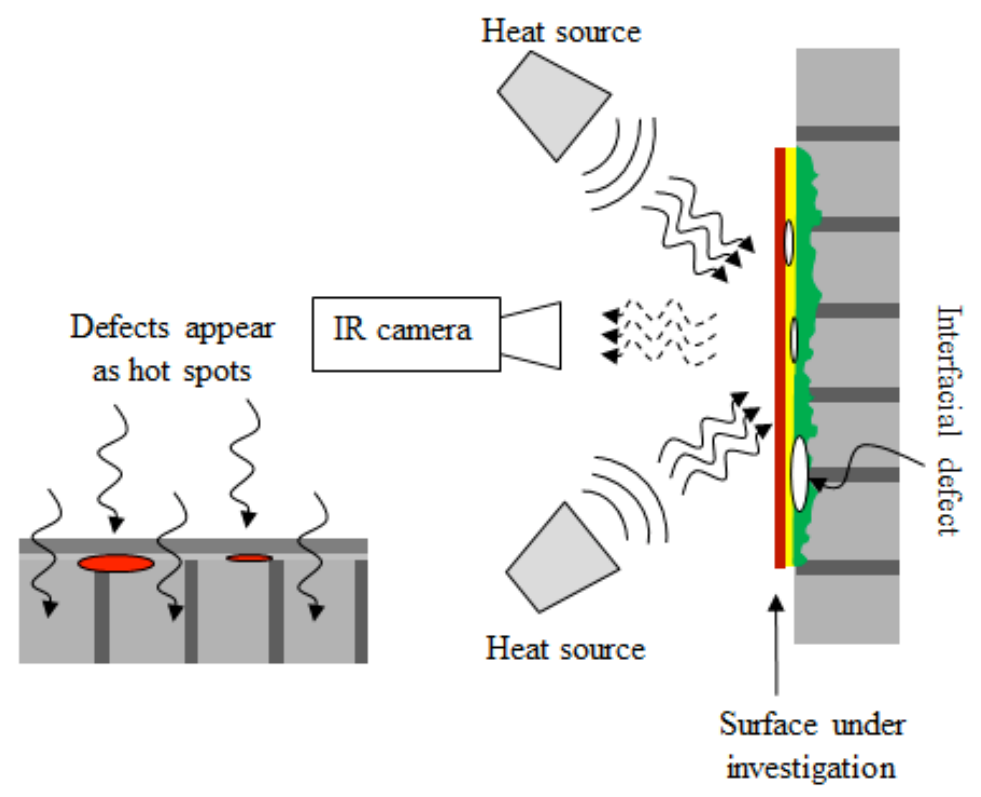

(a)

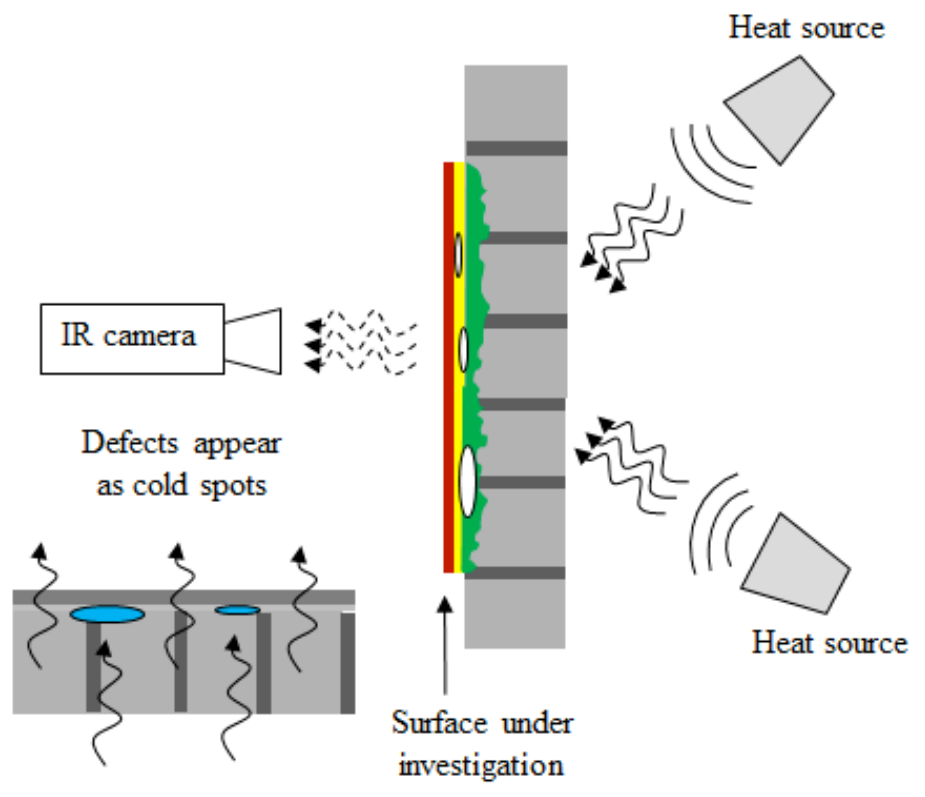

(b)

Fig. 1. Different heat observation methods in IR thermography technique: (a) reflection observation method; (b) transmission observation method. 


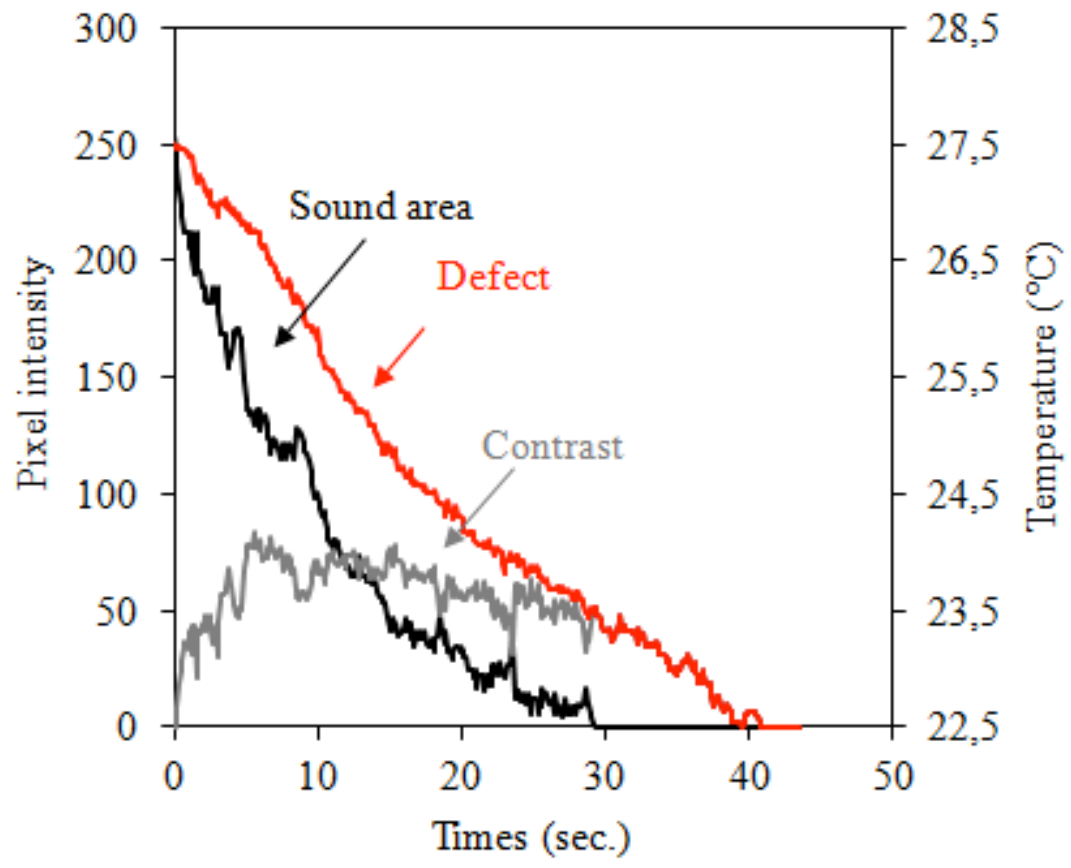

Fig. 2. Thermal history curves of sound and delaminated areas. 


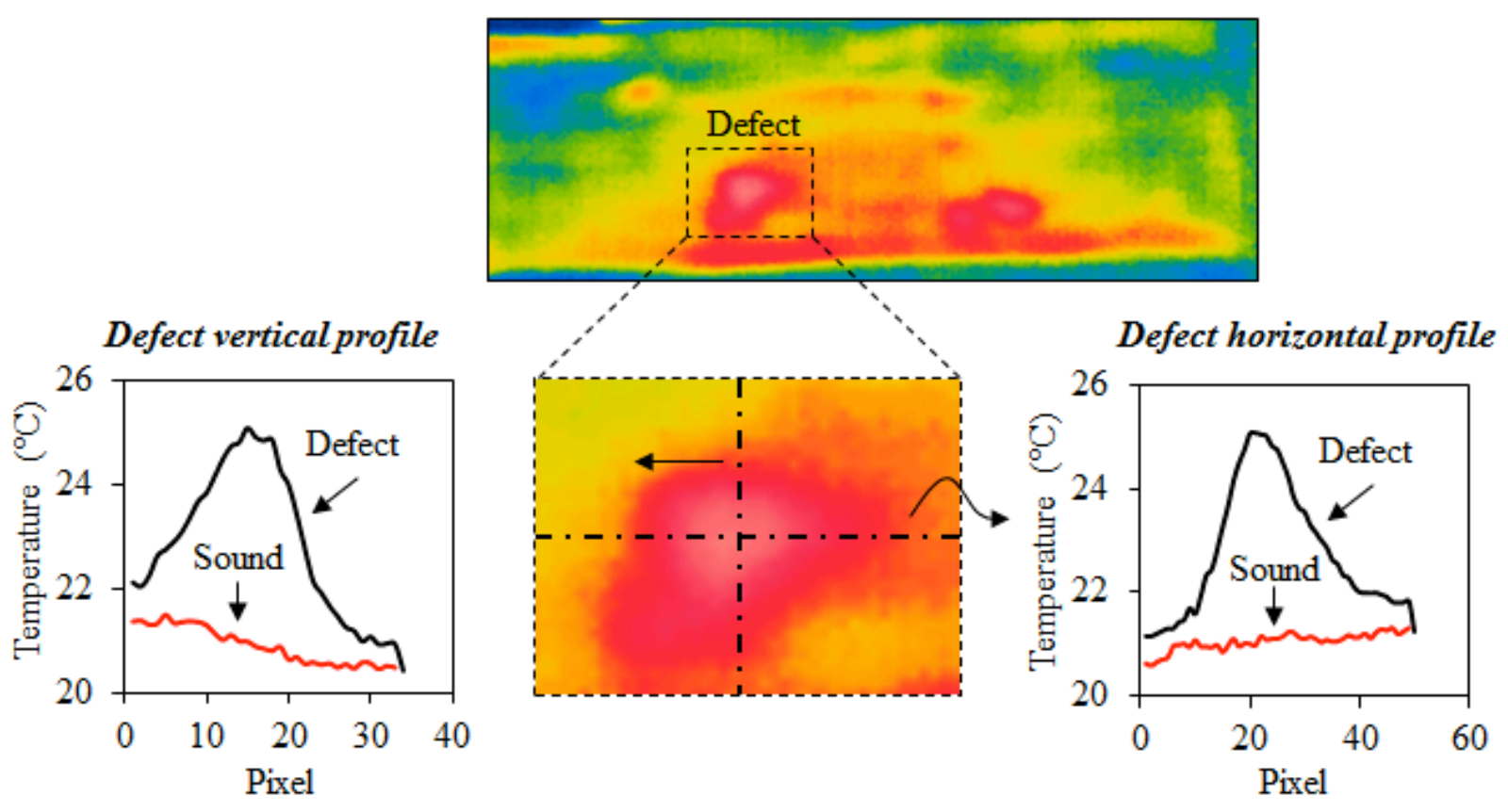

Fig. 3. Thermogram of a defect. 


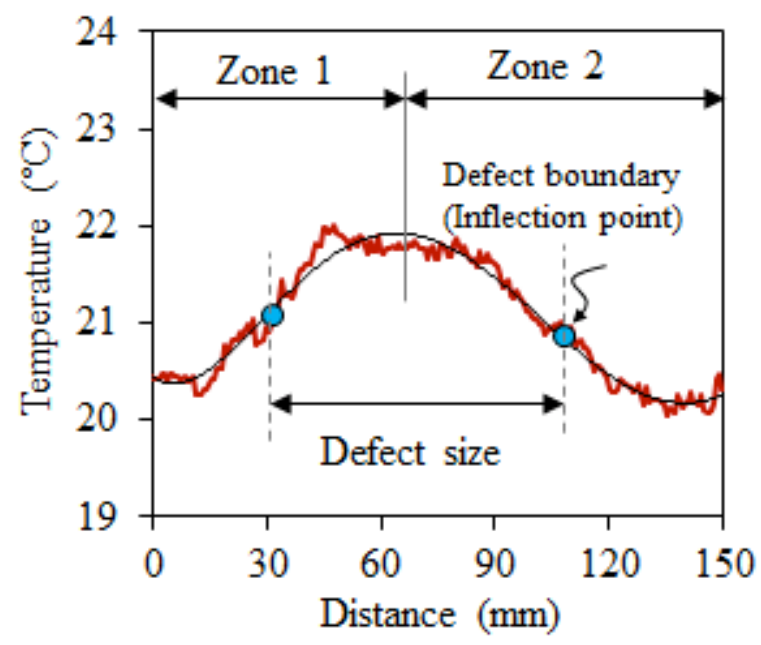

Fig. 4. Defect boundaries. Zone 1 and Zone 2 represent different left and right sections of the defect around the center point. 


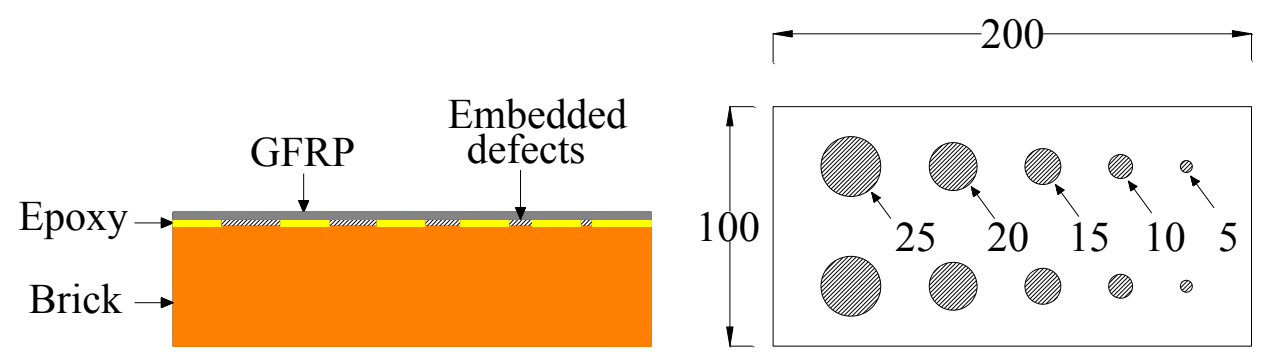

(a)

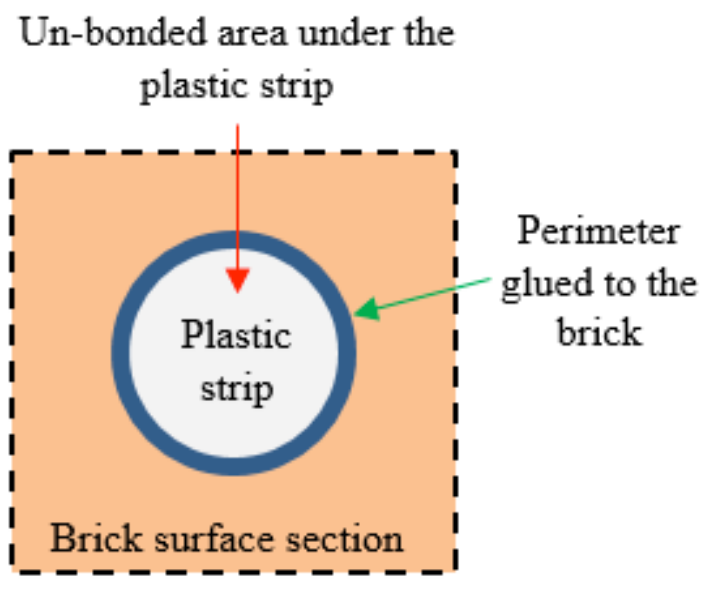

(b)

Fig. 5. Details of the specimens with embedded interfacial defects: (a) defects details; (b) attachment details. 


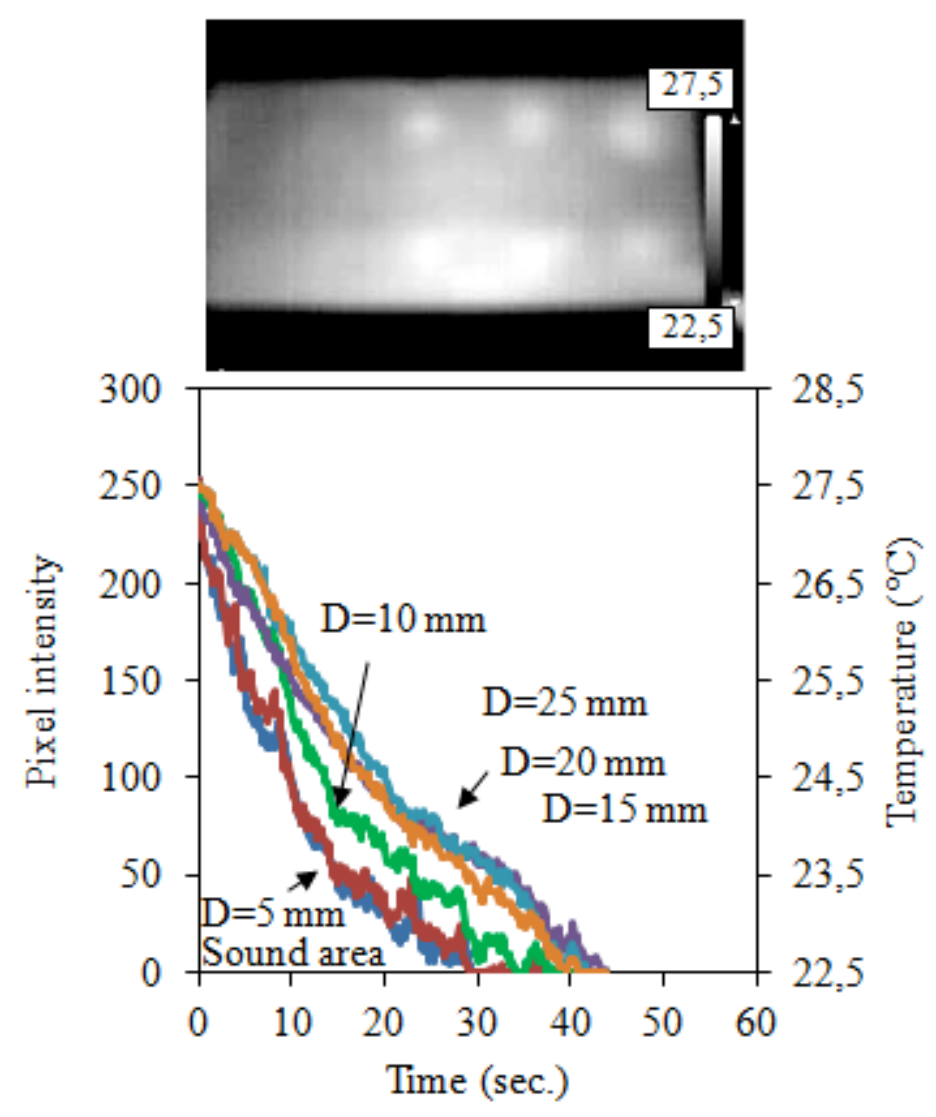

Fig. 6. Thermal history curves at defect locations and a typical thermogram. 


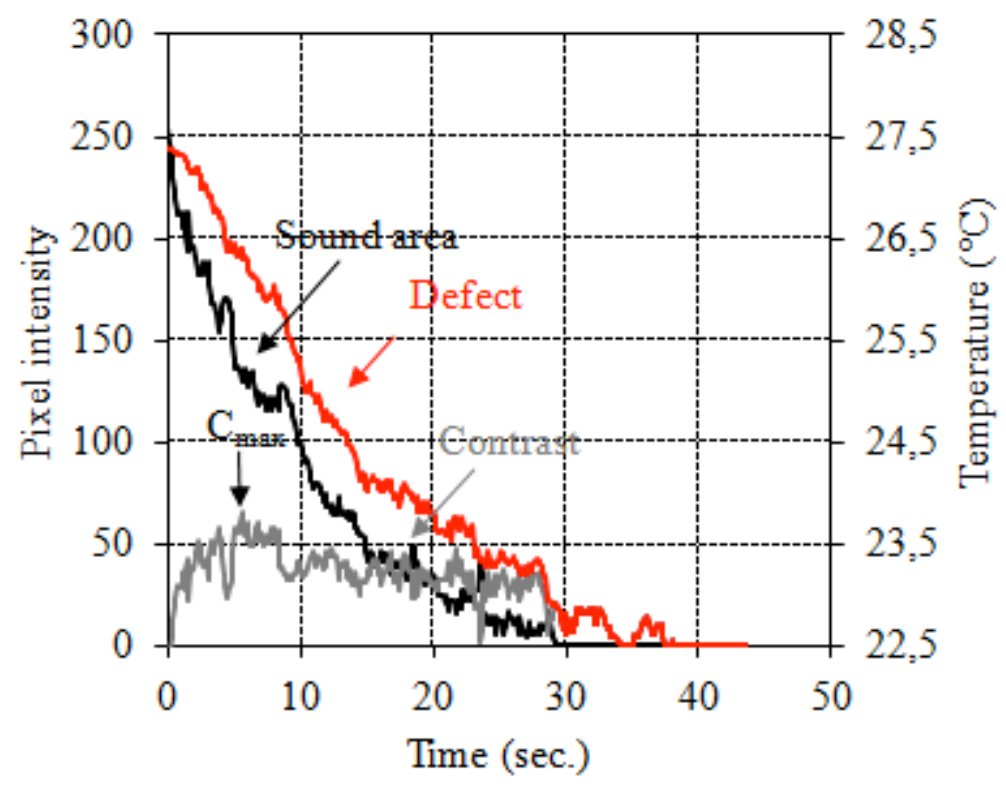

(a)

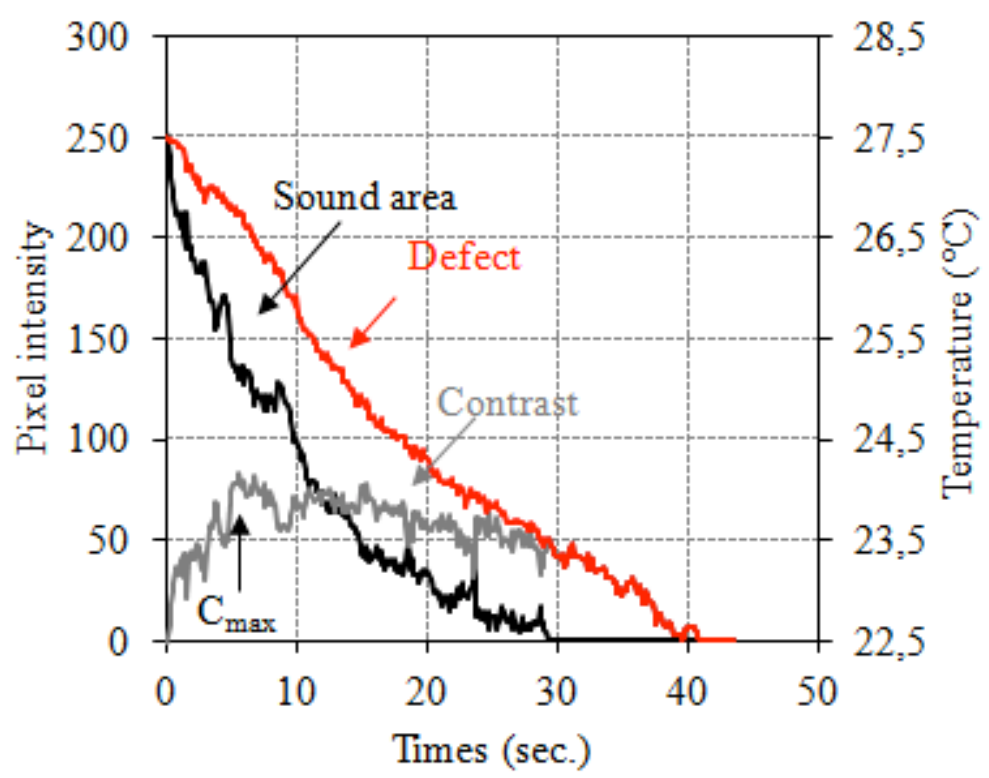

(b)

Fig. 7. Maximum thermal contrast evaluation for: (a) $10 \mathrm{~mm}$ defect; (b) $25 \mathrm{~mm}$ defect. 

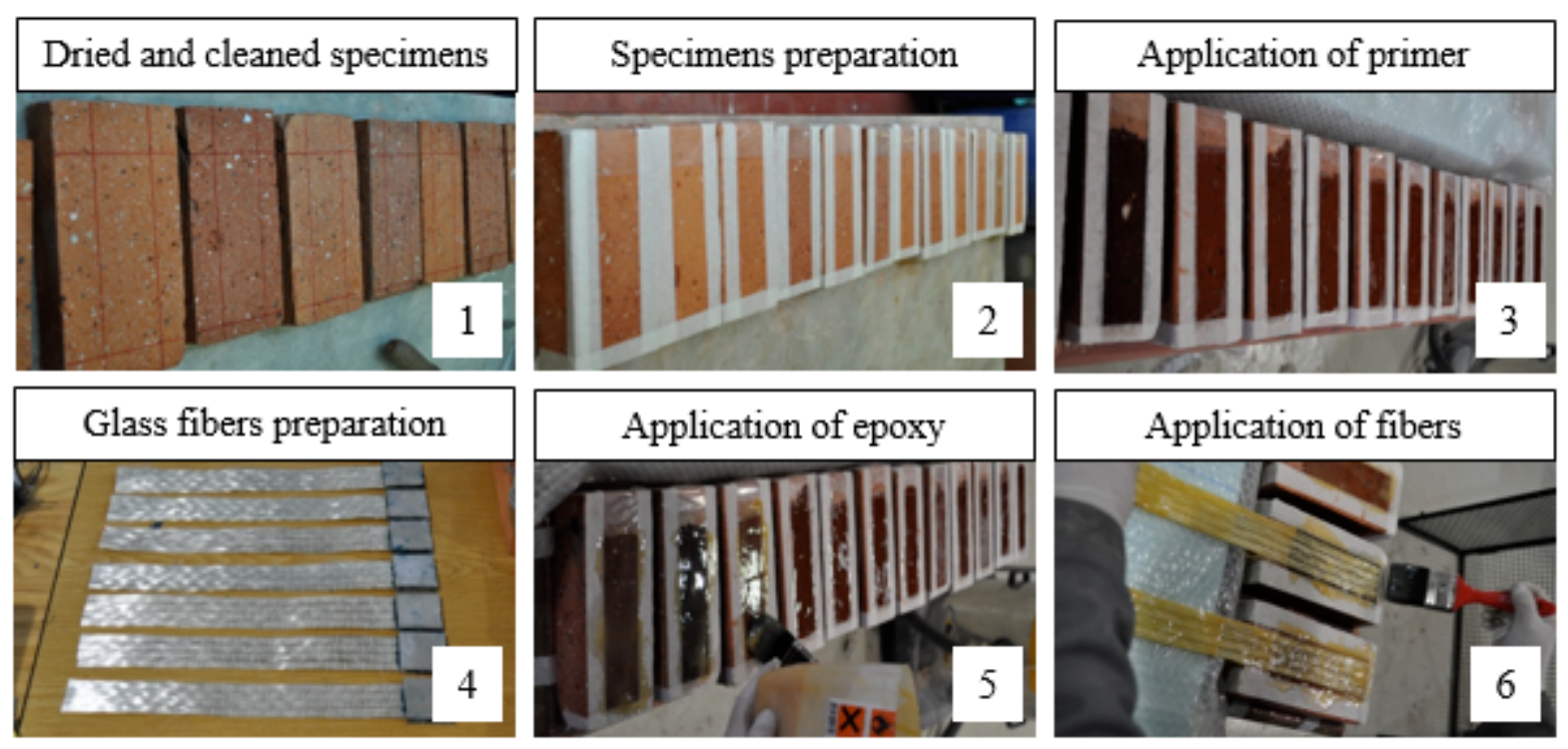

Fig. 8. Preparation of the brick specimens following the wet lay-up procedure. 


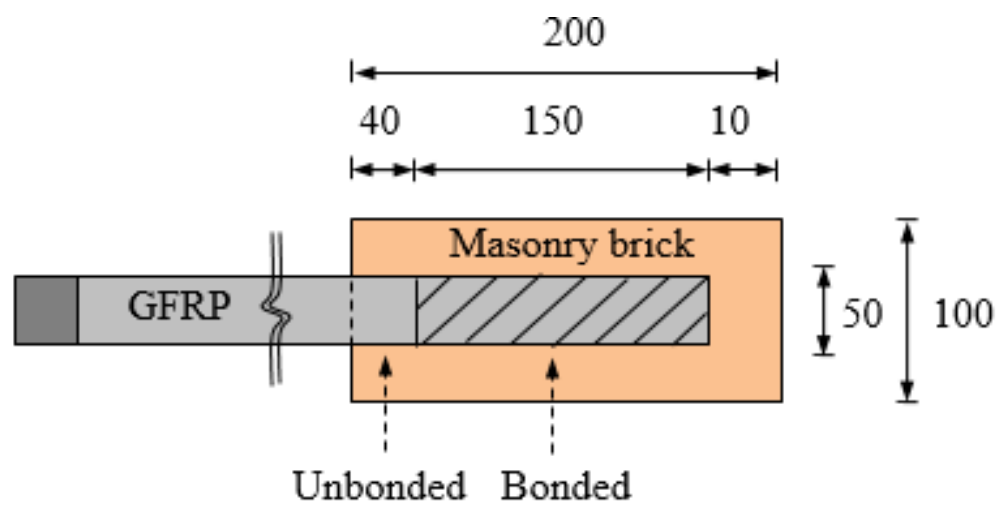

Fig. 9. Details of the specimens used for accelerated ageing tests. 


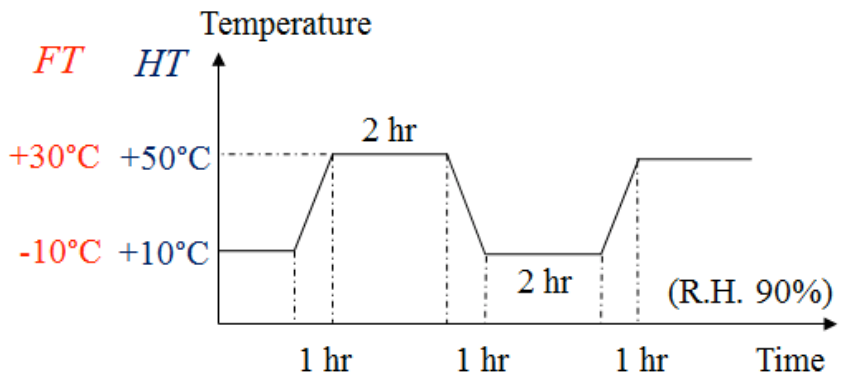

Fig. 10. Accelerated hygrothermal exposures for two different diagrams (FT and HT). 


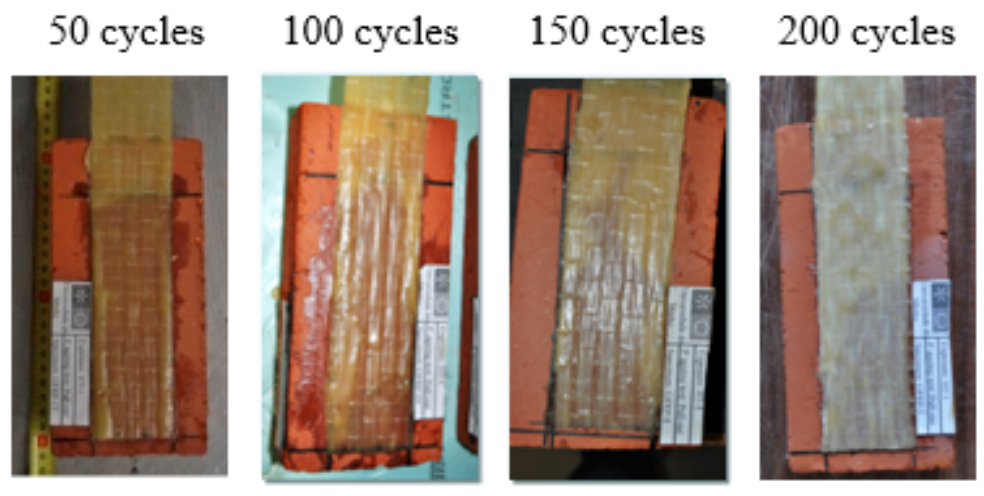

(a)

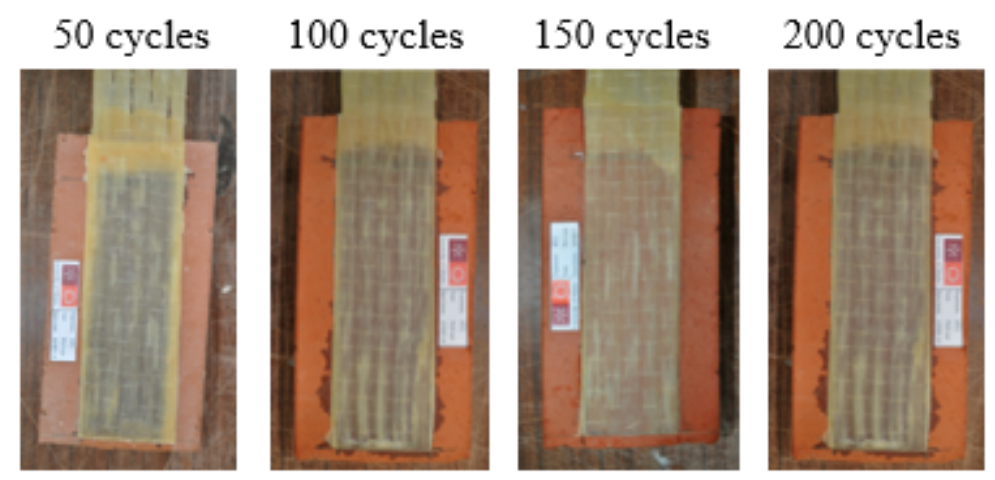

(b)

Fig. 11. Specimens exposed to different periods of: (a) HT exposure; (b) FT exposure. 

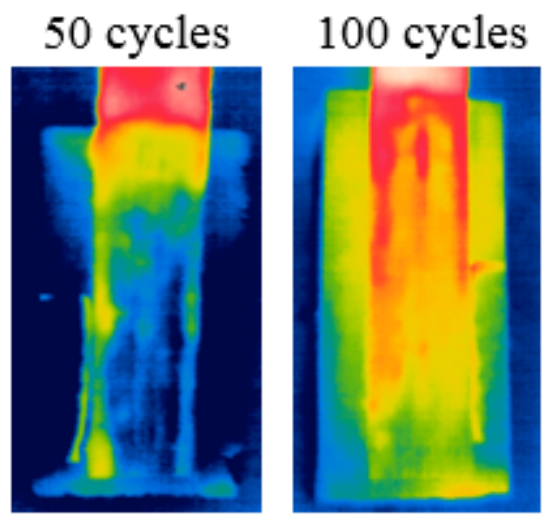

150 cycles

200 cycles
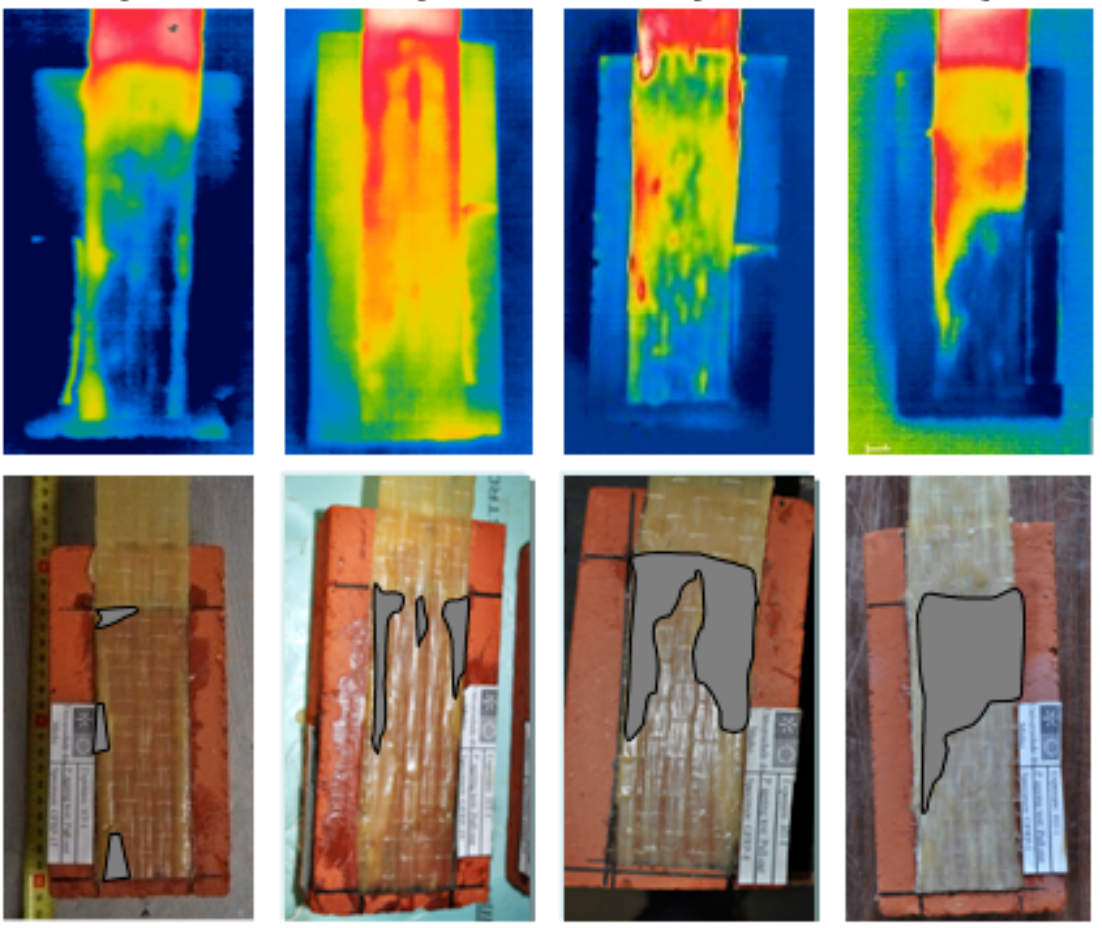

Fig. 12. Qualitative assessment of delaminated areas after different periods of exposure to HT conditions, using IR tomography. 

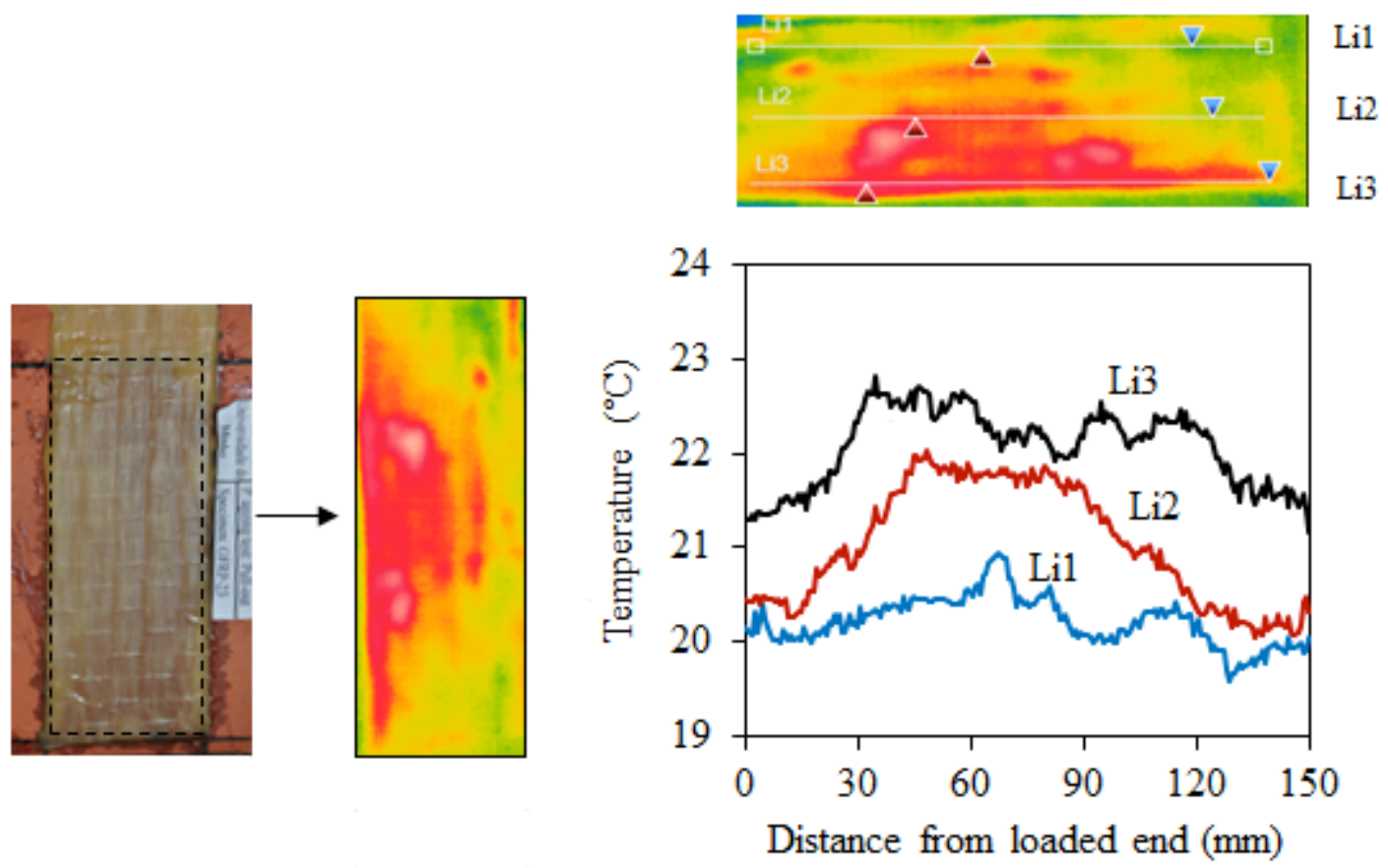

Fig. 13. Temperature profiles in a specimen exposed to 100 cycles of HT exposure. 

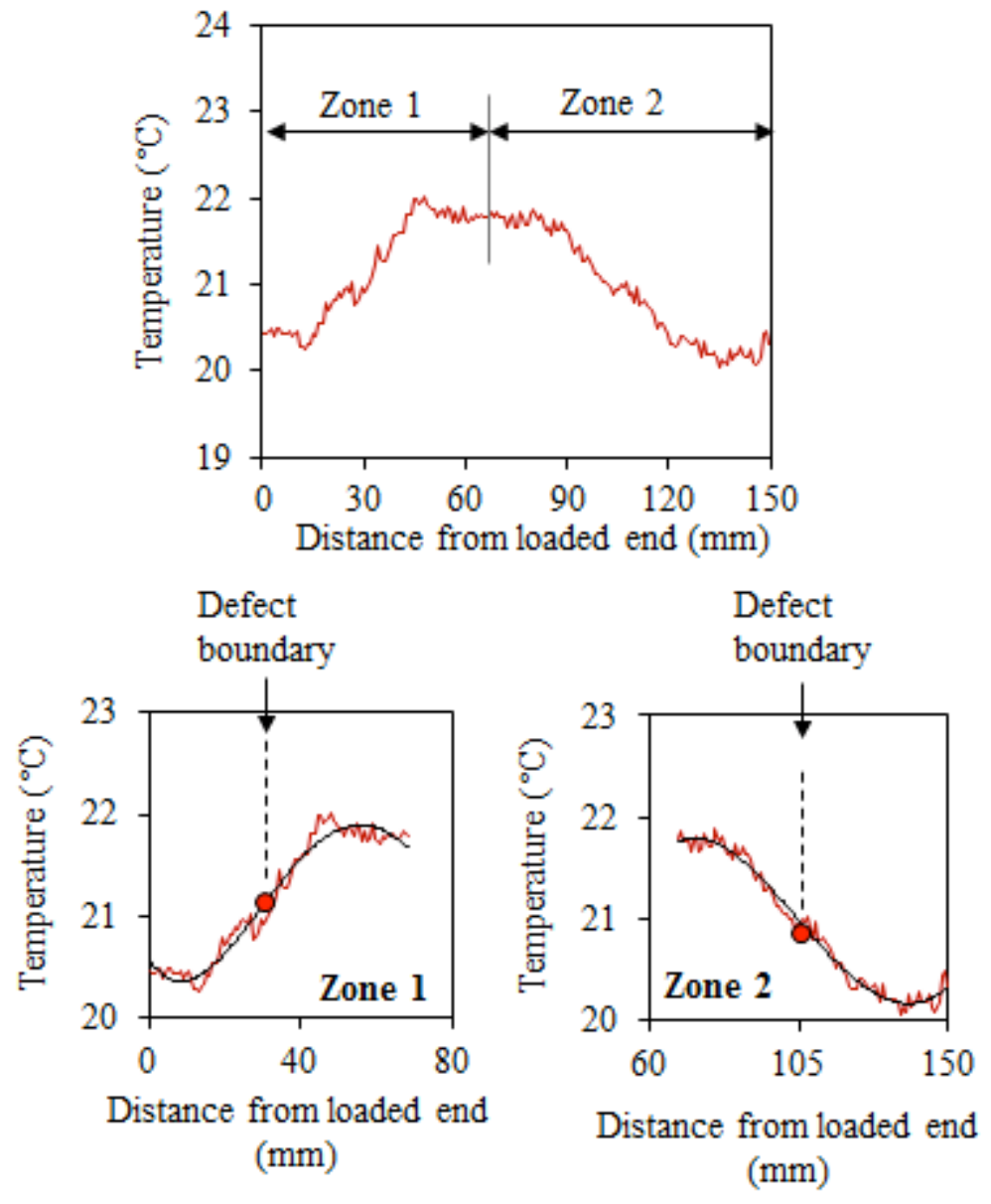

Fig. 14. Delamination boundaries evaluation in a specimen exposed to 100 cycles of HT exposure. 

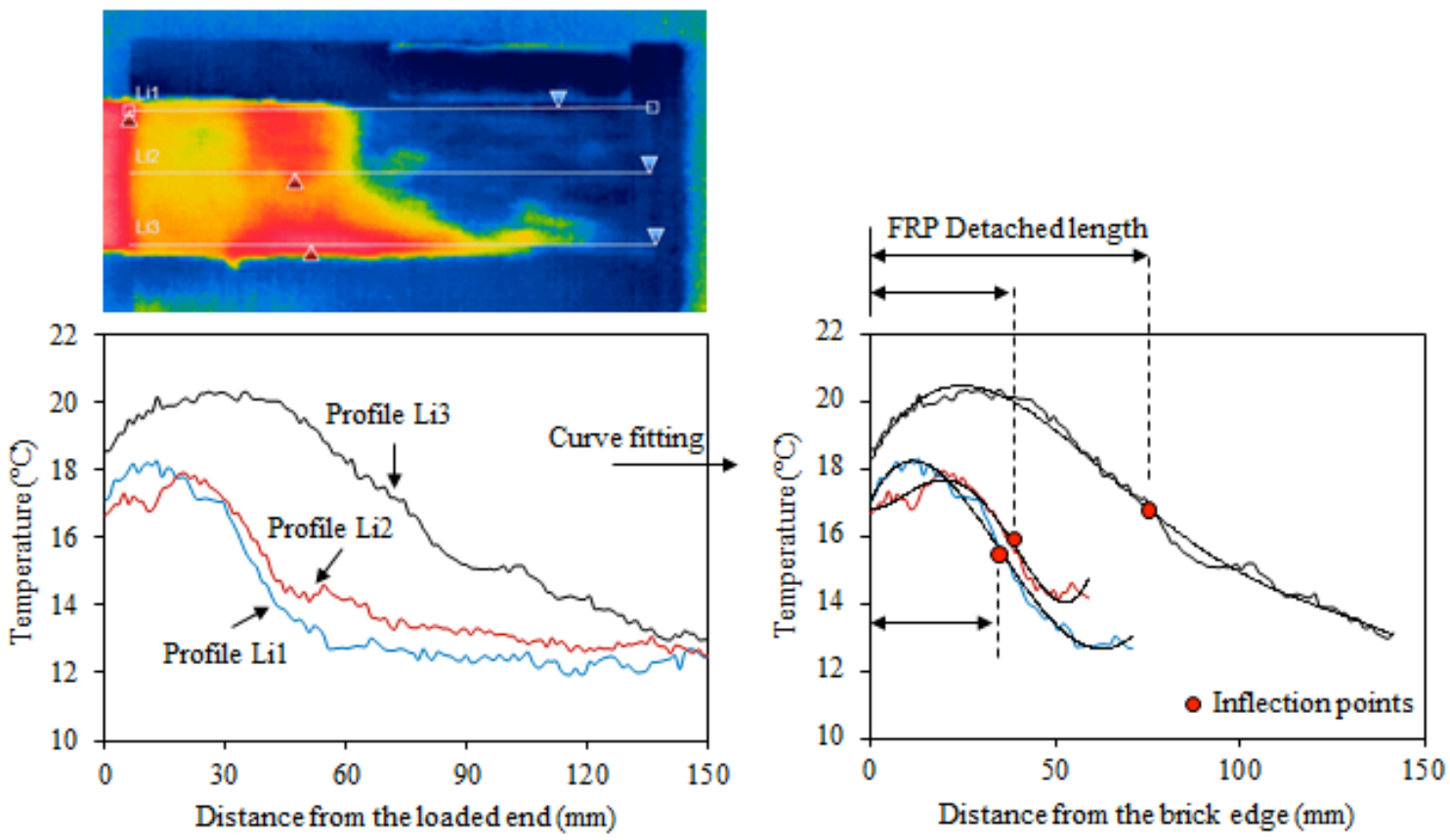

Fig. 15. Temperature profiles and quantitative assessment of delaminated areas in a specimen exposed to 200 cycles of HT exposure. 


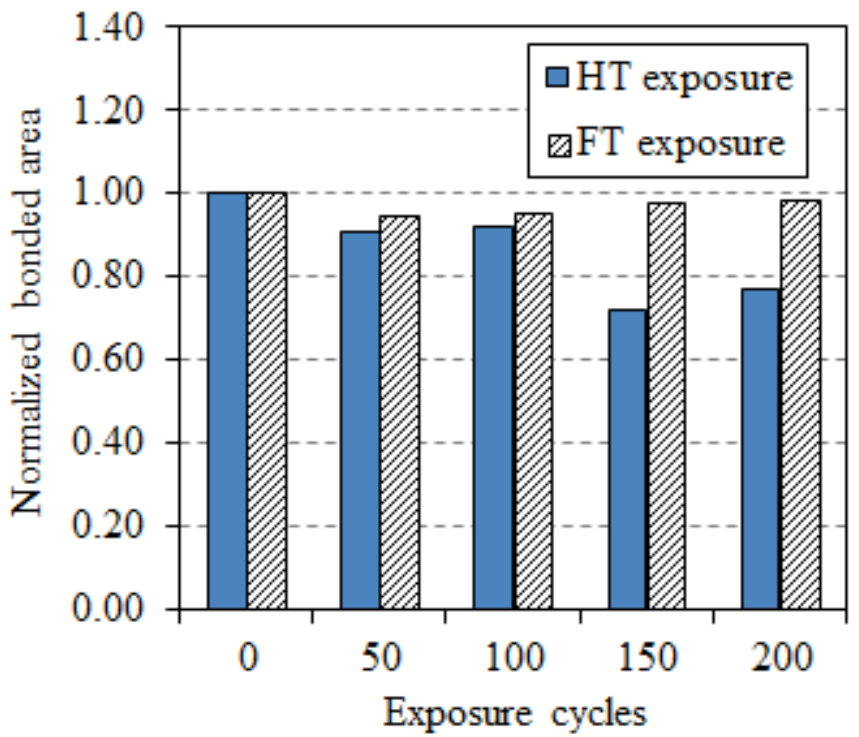

Fig. 16. Reduction of the bonded area with exposure cycles. 